\title{
O corpo envelhecido na percepção de homens idosos
}

\author{
The aged body on the perception of elderly men \\ El cuerpo envejecido en la percepción de hombres ancianos
}

\section{Maria das Graças Melo Fernandes', Loreley Gomes Garcia"}

\author{
' Universidade Federal da Paraíba. Programa de Pós-Graduação em Enfermagem. João Pessoa-PB, Brasil. \\ " Universidade Federal da Paraíba. Programa de Pós-Graduação em Sociologia. João Pessoa-PB, Brasil.
}

Submissão: 28/02/2010 Aprovação: 12/12/2010

\begin{abstract}
RESUMO
Neste estudo exploratório, de natureza qualitativa, objetivamos investigar a percepção do corpo envelhecido por parte de doze homens idosos que aceitaram participar da investigação. A coleta de dados foi realizada mediante uma entrevista semiestruturada, gravada. Na análise do material empírico, utilizamos a abordagem de análise de discurso. Quanto aos resultados, verificamos que alguns idosos percebem seus corpos jovens. Os demais afirmaram possuir corpos alquebrados por doenças e limitações que interferem nas suas funções cotidianas. Apesar disso, apenas de modo muito velado, esses idosos expressam preocupação com a aparência. Suas inquietações primeiras dizem respeito à perda da potência, do vigor e da força física, ou seja, à perda de atributos culturalmente elaborados e socialmente sancionados como características essenciais da masculinidade.
\end{abstract}

Descritores: Corpo; Envelhecimento; Homens; Idoso.

\section{ABSTRACT}

In this exploratory study of qualitative nature, the objective was to investigate the perception of twelve elderly men that freely accepted to participate of the investigation after received information about its purposes and operational procedures. The gathering of data was accomplished under a semi-structured recorded interview. In the analysis of the empirical material was used the approach of speech analysis. As for the results, it was verified that some elderly see their body's young. The others, said to possess weakened bodies by diseases and limitations that interfere in their daily functions. Besides that, only in a very small way, these elderly express worry with appearance. Their first complains are about lost of power, vigor and physical force, i.e., the lost of culturally elaborated and socially sanctioned attributes as essential characteristics of manliness.

Key words: Body; Aging; Men; Elderly.

\section{RESUMEN}

En este estudio exploratorio, de naturaleza cualitativa, objetivamos investigar la percepción del cuerpo envejecido por parte de doce hombres ancianos que aceptaron participar de la investigación. La recopilación de datos fue realizada mediante una entrevista semiestructurada, grabada. En el análisis del material empírico, utilizamos el abordaje de análisis de discurso. En cuanto a los resultados, verificamos que algunos ancianos perciben sus cuerpos jóvenes. Los demás afirmaron poseer cuerpos afectados por enfermedades y limitaciones que interfieren en sus funciones cotidianas. A pesar de eso, apenas de modo muy velado, esos ancianos expresan preocupación con la apariencia. Sus inquietudes primeras se refieren a la pérdida de la potencia, del vigor y de la fuerza física, o sea, la pérdida de atributos culturalmente elaborados y socialmente sancionados como características esenciales de la masculinidad.

Palabras clave: Cuerpo; Envejecimiento; Hombres; Anciano. 


\section{INTRODUÇÃO}

O processo de envelhecimento do corpo é peculiar à individualidade e processos sociais vivenciados por cada ser. Ademais, para além do que somos capazes de apreender do corpo físico, fazemos uma construção imaginária desse corpo, o que fundamenta o processo de identificações ao longo de nossa vida.

Nessa perspectiva, o corpo envelhecido deixa de ser percebido como um produto da natureza e passa a ter assento no campo da cultura, pois é no espaço da subjetividade que se ancora o seu sentido ${ }^{(1)}$. Assim sendo, ele não pode ser representado ou compreendido como entidade em si mesmo ou, simplesmente, um continuum linear, mas como um corpo, num continuum multidimensional no qual a raça, a geração, o gênero, a religião, a classe social formam especificações corporais $^{(2)}$. Mesmo que o homem se conceba autônomo, sua corporalidade não pode escapar dessa ordem de significações mais amplas.

Cabe destacar que o corpo do idoso é singularizado também por traços individuais e marcadores biológicos que possuem significados diferenciados, conforme presentes no corpo masculino ou feminino, isto é, enquanto sexualmente específico, o corpo codifica os significados socioculturais projetados nele de modos sexualmente determinados. Não obstante, nem sempre as expectativas dos que lidam com as questões relativas ao envelhecimento correspondem às demandas dos idosos em relação a sua senescência.

Dada essa realidade, emerge a importância de conhecermos as vivências dos idosos com base em seus próprios relatos. Considerando isso, este estudo teve como objetivo desvelar a percepção do corpo envelhecido por parte de homens idosos.

\section{METODOLOGIA}

Este estudo, de natureza qualitativa, foi originado de tese de doutorado intitulada $A$ velhice e o corpo envelhecido na percepção e vivência de homens e mulheres idosos: uma análise sob o olhar de gênero ${ }^{(3)}$, apresentada ao Programa de Pós-Graduação em Sociologia, da Universidade Federal da Paraíba. O projeto foi aprovado pelo Comitê de Ética em Pesquisa da referida Universidade, sendo registrado sob o protocolo de $n^{\circ}$ 0444. A investigação foi efetivada no grupo de convivência Juventude Acumulada, do bairro popular de Cruz das Armas, do município de João Pessoa - PB -Brasil.

Este recorte do estudo apresenta a percepção do corpo envelhecido de doze homens idosos que aceitaram, livremente, participar da investigação ora mencionada, após receberem informações sobre seu objetivo e seus procedimentos operacionais, e que assinaram o Termo de Consentimento Livre e Esclarecido. A coleta de dados foi realizada nos meses de abril e maio de 2008, mediante uma entrevista semiestruturada, gravada, que foi norteada pelas seguintes questões: como o senhor percebe o seu corpo nesta fase da vida? Pensando em toda a sua vida, o que mais contribuiu para o envelhecimento do seu corpo? Como o senhor percebe o corpo da mulher idosa?
$\mathrm{Na}$ análise do material empírico, utilizamos a abordagem de análise de discurso proposta por Fiorin ${ }^{(4)}$. Considerando essa perspectiva, a discussão desse material foi relacionada ao referencial de gênero para ancorar as posições sociais nele reveladas. O princípio básico desse enfoque consiste na compreensão de que o discurso é uma posição social, devendo, assim, ser analisado, revelando, por inferência, a visão de mundo dos sujeitos que falam.

\section{RESULTADOS E DISCUSSÃO}

Quanto aos achados, verificamos que a maioria (oito) dos idosos refere possuir corpos que guardam muitos atributos da juventude, evidenciando, portanto, poucos problemas. Quando estes emergem, não afetam a sua funcionalidade. Nesse contexto, eles rejeitam explicitamente incluírem-se na categoria social de velho. Afinal, um corpo bem disposto e hígido é um sinal de não velhice. Os depoimentos que se seguem expressam essa avaliação.

... meu corpo é bom, só tem um problema: tive umas dores assim na barriga e foi indo até que parou de vez. O sexo não funcionou mais. Aí eu me aperriei, procurei muitos médicos, mas como eu tenho esse problema de pressão, eles não quiseram passar remédio. Aí foi o tempo que minha velha ficou inutilizada também [sofreu uma fratura de fêmur em consequência de uma queda], aí não deu problema. O resto é bom, tá tudo bem. (Sr. D, 74 anos)

... percebo que meu corpo guarda quase as características da juventude, isto em termos emocionais. (Sr. A, 69 anos)

... não me sinto velho. Não me sinto, porque, como eu tenho a saúde boa, sinto que o corpo envelheceu, mas o espírito não. Então, eu me sinto em plena disposição de continuar fazendo o que aparecer pela frente. (Sr. F, 68 anos)

... percebo o meu corpo muito bem. (Sr. B, 70 anos)

- sinto o corpo mais cansado [...], a fortaleza agora é pequena, mas dá pro gasto. (Sr. C, 71 anos)

... eu não me sinto velho porque estou muito bem e não sinto nada do que dizem que é ficar velho, nem na memória. (Sr. J, 64 anos)

Adentrando no âmago desses discursos, observamos que a idade cronológica desses homens não foi capaz de fazer seus corpos se dobrarem ao peso dos anos, pois a cabeça, a mente como eixo principal da corporalidade, essa ainda se mantém: "sinto que o corpo envelheceu, mas o espírito não". Essa dicotomia entre o corpo e a mente associa-se ao binômio fraqueza/força, ou seja, o corpo como sede da força física vai perdendo o vigor, com o passar do tempo, enquanto que a mente se sobrepõe a ele e se transforma, na salvaguarda desses idosos como indivíduos jovens, conforme reitera essa fala: "percebo que meu corpo guarda quase as características da 
juventude, isto em termos emocionais" (Sr. A, 69 anos).

Do mesmo modo, quando a saúde é boa não se envelhece. Nesse cenário, o avanço da idade é apenas um fato e não uma vivência. Mesmo que o corpo sinalize algumas debilidades, isso ocorre apenas em algumas partes e não no seu todo, embora algumas dessas partes tenham maior significado para suas vidas, a exemplo do sexo: “o meu corpo é bom, só tem um problema, [...] o sexo não funcionou mais. Aí eu me aperreei $[. . .]^{\prime \prime}$ (Sr. D, 74 anos).

Como podemos observar, essa realidade gerou muita preocupação no Sr. D, pois o fato de sua parceira encontrar-se desejosa de sexo ou ativa sexualmente e de ele não apresentar capacidade de "responder" ameaçava sua masculinidade, impulsionando-o para a busca incessante de cuidados médicos. Mas, para o seu "alívio", nesse curso de sua história, sua parceira "também ficou inutilizada" (sexualmente) em decorrência de uma perda física (sequela de acidente vascular cerebral), "aí não deu problema". Certamente, ambos buscaram alicerçar sua relação conjugal a partir de outras ações e valores, na esfera da igualdade, na vivência de uma sexualidade sem a premissa de penetrações e orgasmos, calcada no enternecimento desvirilizante do amor.

A experiência do Sr. D pode ter sido influenciada pelos seus conhecimentos sobre as particularidades da sexualidade no âmbito da velhice. Muitos homens idosos deixam de ter relações sexuais e se tornam impotentes porque não compreendem as mudanças fisiológicas ligadas ao processo de envelhecimento, interpretam-nas como sendo sintomas de impotência. Com sua autoestima baixa, ficam receosos de não conseguir uma ereção e acabam evitando ter relações para não serem confrontados com a frustração( ${ }^{(5)}$.

Do mesmo modo, fatores predisponentes à arteriosclerose (hipertensão arterial, diabetes, câncer de próstata e obesidade) podem comprometer a função erétil e impossibilitar o ato sexual. Outros fatores que, uma vez somatizados, podem levar a uma disfunção erétil, constituem a qualidade do relacionamento com a companheira, incluindo a excessiva preocupação em satisfazê-la, o grau de privacidade para os intercursos sexuais, a perda da atração, a ansiedade, os estímulos eróticos negativos, o status social, entre outros ${ }^{(6)}$. Condições comumente presentes na vivência da sexualidade de pessoas idosas.

Retomando o discurso dos entrevistados, observamos que, apesar de boa parte deles não atribuir sentido ao corpo envelhecido por não vivenciarem tal fenômeno, outros reconhecem e vivem o seu corpo com restrições e marcas que os depreciam. Frente a essa experiência, o retorno à identidade anterior não é mais pensado ou possível, ocorrendo mudanças na vida cotidiana desses idosos.

... o corpo envelhecido é um problema. Com ele você já não tem força nas pernas, você já não pega em peso, você passa a depender dos outros. Tudo isso pesa, minha amiga! (Sr. I, 65 anos)

... esse corpo de hoje é a sobra [...] (Sr. G, 73 anos)
... ah! Na velhice o corpo sente, não tem jeito. É um corpo sem potência. É tudo diferente. Vêm as dores, o namoro não é mais do mesmo jeito, tudo muda. (Sr. L, 67 anos)

... meu corpo hoje está decadente. O envelhecimento do meu corpo representa frustração total. O mal da velhice é essa transformação do corpo [...] Você já não tem mais aquele vigor, aquela força física de sair pra caminhar, ir a um Banco! A mente é cansada, não acompanha. (Sr. M, 71 anos)

Esse grupo de homens ao se posicionarem sobre o corpo envelhecido, ressalta, principalmente, as transformações ocorridas na sua dimensão biológica ou física. Há, assim, por parte dos entrevistados, a denúncia de um corpo alquebrado que padece à passagem do tempo, que perdeu, em graus variados, sua força, sua energia e sua potência, tomando contornos desconhecidos através de modificações. Contudo, esse corpo marcado pela impotência confere a esse senhor uma história pra contar:

eu não tenho um corpo forte, assim resistente, potente, mas tenho muita coisa pra contar. É só olhar para os cabelos brancos [...] Seria bom todo mundo envelhecer pra entender muita coisa da vida. (Sr. L, 67 anos)

Cabe destacar que, na contemporaneidade, especialmente nas sociedades ocidentais, os fatos presentes na memória dos idosos, a exemplo daqueles que o Sr. L têm pra contar, possuem importância secundária, podendo parecer antiquada para os mais jovens. Na época da informação, diminuiu a comunicabilidade da experiência, não há mais conselhos, a busca da sabedoria perdeu as forças, pois, se tudo é relativo, cada um fica com sua opinião ${ }^{(7)}$.

Quanto à estética corporal, apesar de ela estar afetada no envelhecimento, os homens não a referenciam como problema, no entanto não esquecem de pontuar o corpo do seu desejo.

... eu queria ter um corpo novo que me fizesse viver assim uma situação segura, com menos problemas. (Sr. G, 73 anos)

... eu gostaria de ter um corpo jovem, de trinta anos, quando eu tinha os braços fortes. Quando eu era mais simpático do que sou. Eu gostaria de ter permanecido naquele estado. (Sr. I, 65 anos)

... queria ter um corpo novo, mais forte, com mais saúde. (Sr. G,73 anos)

... sinto saudade de quando era mais novo, de quando eu tinha disposição pra trabalhar, de quando eu era forte, sadio. (Sr. H, 68 anos)

Embora não ocorra da mesma forma, nem na mesma época, para todas as pessoas, não podemos negar que, à medida que o tempo se impõe, o corpo se deprecia: a agilidade diminui, a plasticidade vai se tornando rude, a coordenação vai se 
alterando pela falta de preservação do ritmo e da sequência normal dos movimentos, e isso passa a ser motivo de preocupação para os idosos. Nesse contexto, a realidade natural e concreta da velhice é incorporada, sendo este o momento em que o significado do corpo se volta à funcionalidade. Já não é necessário um corpo belo, mas sim um corpo forte e saudável. Afinal, homens que se mantêm vigorosos, mesmo na senectude, parecem ter recebido mais consideração social.

Assim, o ressentimento desses idosos não é com a presença das rugas, flacidez ou cabelos brancos, pois isso é tratado com certa naturalidade dentro do processo de vida masculina, mas com a ausência da robustez e da disposição corporal, pois esses atributos, além de muitos outros, sempre estiveram associados ao ser masculino e foram pensados como qualidades em si positivas, desejáveis, dignas de constarem como aquelas que a própria sociedade contemporânea projeta para os indivíduos ${ }^{(8)}$.

O corpo envelhecido para esses depoentes é medido, além da idade cronológica, por determinadas características físicas e modificações no seu estilo de vida, isto é, as representações sobre seu corpo falam de uma perda gradativa da força, da potência e da independência. Já quando Ihes solicitamos, durante a entrevista, pensarem durante toda a sua trajetória de vida e, nessa reflexão, procurar identificar o que mais contribuiu para o envelhecimento do seu corpo, os idosos assim se posicionaram:

... trabalho, muito trabalho. (Sr. A, 69 anos)

... o trabalho na roça. Trabalhei desde criança mais meu pai. Ele queria que eu saísse cedo de casa e só voltasse quando o sol se escondesse. Aí, não estudei. (Sr. C, 71 anos)

... o trabalho pesado. Sem estudo, fiquei no trabalho pesado. (Sr. D, 74 anos)

... o trabalho deixou o corpo gasto. (Sr. D, 74 anos)

... o trabalho desgasta muito a gente. Sempre fui um homem de muito trabalho, de muita preocupação com o sustento da família. (Sr. L, 67 anos)

$\mathrm{Na}$ leitura dessas falas, observamos que os homens se situam como ex-trabalhadores, como indivíduos que têm "corpos gastos" pelo trabalho pesado, implicando sua condição de gênero, como elemento fundante de seu envelhecimento corporal. A preocupação com o "sustento da família", referida pelo Sr. L, emerge, também, como fator contribuinte para o seu envelhecimento corporal.

Vale salientar que a ideia de "ser provedor", articulada às esferas do trabalho e da família, constitui instância de referência para o reconhecimento do "ser homem" no âmbito da masculinidade hegemônica. A "vida desregrada", permeada especialmente por uma sexualidade instintiva e descontrolada, também atributo dessa expressão de masculinidade, é apontada pelo Sr. G como um comportamento envolvido no fato de ele ter um corpo problemático, sem saúde.
... eu tive uma vida desregrada, aí hoje vejo os problemas. Arrumei umas doenças porque eu era da farra, do namoro! Dava umas puladinhas de cerca! Eu tive um par de mulheres na vida. Minha esposa nunca desconfiou. Hoje, meu corpo sofre, não aguenta mais, tá desmantelado [...] Também nunca fui de procurar médico. Quando sentia alguma coisa, tá certo que era pequena, eu resolvia em casa mesmo (Sr. G, 73 anos).

O uso do álcool, ainda um comportamento fortemente associado à masculinidade idealizada nessa geração ${ }^{(9)}$, também foi pontuado por alguns homens como um fator desencadeante das suas modificações corporais, especialmente pelo seu adoecimento.

... acho que as mudanças do meu corpo vieram da bebida, mas já venci esse problema. Agora, só quando adoeci. (Sr. E, 72 anos)

... nada contribuiu mais para o envelhecimento do meu corpo do que a bebedeira. Já tive até doença no fígado. Agora tou proibido. (Sr. I, 65 anos)

Esse evento, entre outros fatores, pode ter recebido influência do modo como os homens enfrentam o trato de sua saúde e de seu corpo. Os homens, por se sentirem invulneráveis, se expõem mais a riscos, a exemplo do uso de substâncias, e acabam ficando vulneráveis ${ }^{(10)}$. Associadas a isso, encontram-se fortalecidas suas dificuldades de verbalizar as próprias necessidades de saúde, pois falar desses problemas pode significar uma possível demonstração de fraqueza, de feminização perante os outros ${ }^{(11)}$.

Considerando o exposto, verifica-se que o gênero tem grande força explicativa do status de saúde declarado pelos idosos, especialmente da morbidade percebida ${ }^{(12)}$. Fatores culturais determinam menor expressão de desconfortos ou necessidade de cuidados entre os homens do que entre as mulheres, independentemente do status socioeconômico e do tipo de arranjo familiar.

$\mathrm{O}$ fato de os homens tenderem a receber mais cuidados domésticos [principalmente das mulheres] do que as mulheres também pode influenciar a busca mais tardia de ajuda profissional por parte deles, os quais passam a requerer este auxílio apenas quando os cuidados ora referidos não forem mais suficientes ${ }^{(13)}$.

Por fim, suscitamos os homens a realizarem a seguinte reflexão: como o senhor percebe o corpo da mulher idosa? Neste questionamento, averiguamos a produção de um discurso que aponta o corpo da mulher, quando comparado com o deles, como um corpo "mais fraco".

... a mulher evita muitas coisas. É mais reservada e, por isso, evita muitos problemas, mas na velhice seu corpo é mais fraco. (Sr. B, 70 anos)

... tem hora que eu acho que o corpo da mulher é melhor. A mulher é dura de morrer! Olha quantas tem aqui! Tudo 
fazendo física! [sorriso]. Eu digo isso, mas se eu me basear pelo o que eu sinto, aí eu acho que o corpo do homem é mais resistente, né? Porque elas tão aí, mas muitas têm doença. Pode perguntar? Muito mais que eu. (Sr. A, 69 anos)

... a mulher sente mais a velhice do que o homem. (Sr. D, 74 anos)

... Mulher é mulher! É um corpo mais fino, mais fraco. Aí na velhice é pio.r (Sr. F, 68 anos)

Compreendemos que essa concepção dos idosos de que o corpo da mulher é mais fraco, e se torna mais frágil ante a velhice, é referendada por um processo histórico e cultural, presente desde a antiguidade, que se consolida após o século XVIII com o discurso e as práticas médicas, guardando alguns vestígios na contemporaneidade, que postula um corpo ontologicamente diferente para o masculino e para o feminino, dotando este de uma inferioridade dada pela natureza ${ }^{(14)}$, ou seja, nesse pensamento dicotômico e assimétrico, que sempre hierarquiza um dos polos, o corpo feminino é sempre tratado como o outro no par de opostos: o inferior. Esse pensamento se distancia do entendimento da situação e do espaço que o corpo, seja masculino ou feminino, ocupa no cenário sócio-político, e afeta as representações e autorrepresentações do gênero.

Não obstante, esse entendimento relativo ao corpo feminino não foi unânime entre os homens, encontramos o Sr. I, que se coloca com um pensamento mais avançado, "um pouquinho acima", do que aquele manifesto pelos demais depoentes e se opõe a tal crença.

O corpo da mulher idosa é o mesmo corpo envelhecido do homem; agora, a sociedade é louca, imbecil e idiota. Ela é falsa. Aí vêm os valores sociais, por exemplo: se você encontrar um homem idoso ainda namorador, a sociedade fica quietinha, mas se você encontrar uma mulher idosa ainda namorando, a história é outra, completamente diferente. Agora eu penso assim porque eu vejo um pouquinho acima. (Sr. I, 65 anos)
Cabe destacar que, nos mecanismos de comparação social, se observam diferenças de sentido nos pensamentos empregados para se referir aos homens e às mulheres idosas, contribuindo para a cristalização de preconceitos que suscitam representações distintas para o corpo masculino e feminino, bem como para suas vivências, incluindo a sexual, marcando diferenças na maneira de homens e mulheres lidarem com o próprio desejo, sendo as mulheres as mais afetadas por esses preconceitos $^{(15-16)}$.

\section{CONSIDERAÇÕES FINAIS}

Os dados produzidos neste estudo revelam, parcialmente, uma realidade que foi recortada e que traduz experiências que estão sendo gestadas de modo particular, retratando, em parte, a realidade de homens idosos que nos falam do seu corpo envelhecido, bem como de sua concepção acerca do corpo da mulher na senescência.

Na leitura desse fenômeno, encontramos alguns idosos que percebem seus corpos ainda jovens, afastando de si possíveis vestígios de velhice, e outros, que visualizam sua dimensão corporal frágil e disfuncional, corroborando com a proposição de que o envelhecimento é um evento universal que gera problemas comuns, mas que podem ser vividos e resolvidos diferentemente de indivíduo para indivíduo, inclusive dentro de uma mesma cultura.

A percepção do corpo da mulher idosa expressa por parte dos homens entrevistados é formatada a partir da crença de que ela possui corpo frágil ou fraco, revelando marcas da sua identidade de gênero elaborada no curso de um processo social e histórico, que imprime às mulheres uma suposta deficiência corporal para justificar as desigualdades sociais entre os gêneros das quais elas são vítimas.

$\mathrm{O}$ todo aqui apresentado encerra a velhice e, consequentemente, o corpo envelhecido numa pluralidade de experiências individuais que impossibilita retê-la num conceito único ao investigá-la, deixando ao alcance do pesquisador somente a possibilidade de confrontar diferentes formas de envelhecimento uma com as outras, e a tentativa de desvelar as razões de suas divergências.

\section{REFERÊNCIAS}

1. Ferreira MLM. O retrato de si. In: Leal OF, organizador. Corpo e significado. $2^{\mathrm{a}}$.ed. Porto Alegre: Editora UFRGS; 2001. p. 409-22.

2. Grosz E. Corpos reconfigurados. Cad. Pagu 2000; 11: 45-86.

3. Fernandes MGM. A velhice e o corpo envelhecido na percepção e vivência de homens e mulheres idosas: uma análise sob o olhar de gênero [tese]. João Pessoa (PB): Programa de Pós-Graduação em Sociologia, Universidade Federal da Paraíba; 2009.

4. Fiorin JL. Elementos de análise do discurso. $13^{\mathrm{a}}$. ed. São Paulo: Contexto; 2005.
5. Vasconcelos D, Novo RF, Castro OP, Vion-Dury K, Ruschel A, Couto MCPP, et al. A sexualidade no processo do envelhecimento: novas perspectivas - comparação transcultural. Estud. psicol. (Natal) 2004; 9(3): 413-19.

6. Batista L. Entre o biológico e o social: homens, masculinidade e saúde reprodutiva. In: Goldemberg P, Marsiglia RMG, Gomes MHA. O clássico e o novo: tendências, objetos e abordagens em ciências sociais e saúde. Rio de Janeiro: Fiocruz; 2003. p. 209-22.

7. Bosi E. Memória e sociedade: lembranças de velhos. $13^{\mathrm{a}}$. ed. São Paulo: Companhia das Letras; 1994. 
8. Oliveira PP. A construção social da masculinidade. Belo Horizonte: Editora UFMG; 2004.

9. Villela W. Gênero, saúde dos homens e masculinidades. Ciênc. saúde coletiva 2005; 10(1): 18-34.

10. Gomes NP, Nascimento EF, Araújo FC. Porque os homens buscam menos os serviços de saúde do que as mulheres? Cad. Saúde Pública 2007; 23(3): 565-74.

11. Figueiredo W. Assistência à saúde dos homens: um desafio para os serviços de atenção primária. Ciênc. saúde coletiva 2005; 10(1): 105-9.

12. Romero DE. Diferenciais de gênero no impacto do arranjo familiar no status de saúde dos idosos brasileiros.
Ciênc. saúde coletiva 2002; 7(4): 777-94.

13. Neri AL. Feminização da velhice. In: Neri AL, organizador. São Paulo: Editora Fundação Perseu Abramo; 2007. p. 47-65.

14. Laqueur T. Inventando o sexo: corpo e gênero dos gregos a Freud. Rio de Janeiro: Relume/Dumará; 2001.

15. Mori ME, Coelho VLD. Mulheres de corpo e alma: aspectos biopsicossociais da meia-idade feminina. Psicol. Refl. Crít. 2004; 17(2): 177-87.

16. Almeida T, Lourenço M. L. Envelhecimento, amor e sexualidade: utopia ou realidade? Rev. Bras. Geriatr. Gerontol. 2007; 10(1): 101-13. 